Check for updates

Cite this as: $B M J 2022 ; 376: 0535$ http://dx.doi.org/10.1136/bmj.0535 Published: 01 March 2022

\section{Russian doctors, nurses, and paramedics demand an end to hostilities in Ukraine}

We, Russian doctors, nurses, and paramedics, strongly oppose the military actions carried out by Russian armed forces on the territory of Ukraine. We are not looking for the guilty and we do not judge anyone. Our mission is to save human lives. It is difficult to imagine a profession more humane than a doctor. And now, at this difficult time for both countries, we call for an immediate cessation of hostilities and for the resolution of all political issues exclusively by peaceful means.

As always, we do not divide the people into friends and foes. We swore to help any human, regardless of nationality, religion, or political views. But today our help is not enough. The war will take many lives and cripple so many destinies that we will not have time to help despite all possible efforts. Everyone will scream in pain and cry out to their mothers in the same language. Any projectile or bullet, even if it does not reach its target and does not take someone's life, still brings fear, panic, and pain. Pain which contracts hearts. Everyone's heart is hurting now. Civilians'. Soldiers'. Soldiers' mothers and wives. Children's. Nobody deserves this fear. Nobody deserves to be killed or injured. Accidentally or intentionally.

Our relatives, friends, patients. and colleagues are located on the attacked territories. There is not a single person among them who would benefit from the ongoing bloodshed. We cannot stay away from pain and suffering, which are increasing every minute.

Human life is priceless. It takes a moment to be killed in action, while the treatment and recovery of the victims can take years. And for the moments of today's war, we will pay for many years after. No matter how the use of lethal weapons is justified, they remain deadly. Deadly and causing pain and suffering. Therefore, following our oaths and maintaining a humane and equal treatment of all lives, we demand an immediate suspension of all operations with the use of lethal weapons.

This open letter is translated from Russian. It was originally published on https://madmed.media/open-letter/ 